\title{
Fulfillment of physical activity guidelines in the general population and frailty status in the elderly population
}

\section{A correlation study of data from 11 European countries}

\author{
Sandra Haider · Igor Grabovac (iD · Thomas E. Dorner
}

Received: 3 July 2018 / Accepted: 24 October 2018 / Published online: 12 November 2018

(C) The Author(s) 2018

\begin{abstract}
Summary
Background We report on the correlation between the proportion of people who fulfil the recommended amount of aerobic physical activity in the general population and the prevalence of frailty or prefrailty in the population $\geq 65$ years in 11 European countries (Austria, Czech Republic, Denmark, Estonia, France, Germany, Italy, Luxembourg, Slovenia, Spain and Sweden). In a subgroup analysis, it was assessed if people who do aerobic physical activity also do strength training.

Methods Aggregated physical activity data were taken from the European Health Interview Survey with the minimum effective sample size of 90,036 participants. Data on frailty status were taken from the Survey of Health Ageing and Retirement in Europe (SHARE) study $(N=24,590)$. For the subgroup analysis, data of the Austrian Health Interview Survey (ATHIS) $(N=15,770)$ were included.

Results The results indicate a significant negative correlation between the proportion of people fulfilling the minimal aerobic physical activity recommendations ( $\geq 150 \mathrm{~min} /$ week) and the proportion of prefrail or frail people $(\mathrm{R}=-0.745 ; p=0.008)$. The correlation between the optimal aerobic physical activity recommendations ( $\geq 300 \mathrm{~min} /$ week) and the proportion of prefrail or frail individuals was $\mathrm{R}=-0.691(p=0.019)$. In both data sets a north-south gradient was seen. Austrian data showed that $52.0 \%$ of the participants fulfilled the minimal aerobic physical activity recommendations and conducted strength training, whereas
\end{abstract}

S. Haider · I. Grabovac $(\bowtie) \cdot$ T. E. Dorner

Department of Social and Preventive Medicine, Centre

for Public Health, Medical University of Vienna,

Kinderspitalgasse 15/1, 1090 Vienna, Austria

igor.grabovac@meduniwien.ac.at
$18.4 \%$ did not fulfil the aerobic recommendations but performed strength training $(p<0.001)$.

Conclusions By taking into account that the number of people $\geq 65$ years will increase in the future these results may be relevant in planning public health interventions for the whole population with the goal of reducing frailty in the elderly.

Keywords Demographic shift · Frailty · Aerobic physical activity recommendations $\cdot$ North-south gradient . Strength training

\section{Introduction}

Frailty is a geriatric syndrome characterized by increased vulnerability and is associated with higher risk of disabilities, falls, morbidity, hospitalization, nursing home admission, and mortality [1-3]. As such it presents a substantial public health concern associated with increased healthcare costs $[4,5]$. As regular physical activity has beneficial effects on maintaining functional status (e.g. muscle strength) and psychological issues (e.g. reduction of depression) as well as preventing chronic diseases (e.g. hypertension, cancer) and improving social outcomes (e.g. social network, social support), it is an important component in prevention and treatment of frailty $[6,7]$.

In adults, according to the national and international physical activity recommendations a multicomponent training regimen comprising aerobic and strength training is recommended $[8,9]$. Concerning aerobic physical activity at least $150 \mathrm{~min}$ of moderate intensity or $75 \mathrm{~min}$ of vigorous intensity weekly is recommended. Optimally, $300 \mathrm{~min}$ of moderate intensity or $150 \mathrm{~min}$ of vigorous intensity physical activity are needed. This regular endurance training increases physical endurance, bone mineral density, fat mass and insulin sensitivity [10]. Furthermore, it 
decreases blood pressure, resting heart rate and basal insulin levels; however, endurance training does not significantly increase muscle mass [10]. Therefore, additional strength training twice a week is recommended [8, 9]. These recommendations also apply for the elderly population [8, 9]; however, in the aging population, strength training is particularly important, as sarcopenia, defined as low muscle mass in combination with low muscle strength or muscle performance [11], plays a relevant role. Both the decline in muscle mass [12, 13] and the decline in muscle strength [14-16] can be delayed with strength training $[6,17]$.

Based on this knowledge, it is postulated that the amount of physical activity in the general population is correlated with the prevalence of frailty in the elderly population. Thus, the aim of these analyses was to assess if countries where the adult population fulfils the recommended amount of aerobic physical activity is in correlation with the proportion of prefrail or frail elderly ( $\geq 65$ years) individuals. Additionally, as especially strength training effects muscle mass and strength $[17,18]$ and reduces the risk of developing frailty, the study aimed to assess if people who reported doing aerobic physical activity also do strength training.

\section{Methods}

\section{Data sources}

For the purpose of this correlation study three data sources were used:

- European Health Interview Survey (EHIS): to assess aerobic physical activity, we used the aggregated data set of the EHIS (Wave 2; 2013), where data of subjects aged 15 years and older on time spent doing health enhancing aerobic physical activity were collected from 28 European countries [19]. The time spent in aerobic physical activity was assessed with the validated European Health Interview Survey Physical Activity Questionnaire (EHISPAQ) [20]. The percentages of persons reaching "0 min”, “1-149 min”, “ $\geq 150$ min” and “ $\geq 300$ min” of moderate aerobic physical activity were reported. In this data the amount of strength training was not assessed.

- Survey of Health, Ageing and Retirement in Europe (SHARE): for the assessment of the frailty status, the SHARE study (Wave 5; 2013) data were used [21]. In this study, data from persons aged $\geq 65$ years and living in households were used. From all collected data, the items "exhaustion", "weight loss", "weakness", "slowness" and "low activity" were used. Based on the SHARE frailty index [22], the discreet factor score was calculated and individuals were categorized as: 1) robust, and 2) prefrail or frail. Persons who did not answer or had missing values in any of the necessary items were excluded from the analysis.

Finally, data from 11 countries (Austria, Czech Republic, Denmark, Estonia, France, Germany, Italy, Luxembourg, Slovenia, Spain, Sweden) were included as both data on aerobic physical activity and the prefrailty/ frailty prevalence were available. In these investigated 11 countries the minimum effective sample size of the EHIS was calculated to be 90,036 and data from 24,590 individuals of the SHARE study were available.

- Austrian Health Interview Survey (ATHIS): as strength training was not assessed in the EHIS, and the study aimed to investigate if people fulfilling the aerobic physical activity were also likely to fulfil the recommendation for strength training, a subsample analysis was carried out, including the individual-based data from the Austrian part of the EHIS, the ATHIS 2014, were used [23]. The dataset comprised 15,770 subjects aged 15 years or older. The proportion of individuals fulfilling the minimal aerobic physical activity recommendation and the proportion of people conducting strength training at least twice a week were used. Aerobic physical activity was also assessed with the validated European Health Interview Survey Physical Activity Questionnaire (EHIS-PAQ) [20], whereas strength training was assessed with the question "On how many days a week do you conduct exercises aiming to strengthen your muscles?".

\section{Statistical analysis}

The lowest and also the highest value of the EHIS data concerning the proportion of people in different aerobic physical activity categories are presented. Continuous normal distributed data of the SHARE study are presented as mean values and standard deviation (SD), and categorical variables in percentages, including minimum and maximum values seen in the respective countries. Spearman correlation coefficients were calculated to observe the associations between the proportion of individuals fulfilling the minimum recommendations for aerobic physical activity per week and the proportion of prefrail/frail individuals. The same was done with the criteria of optimal aerobic physical activity recommendation and the proportion of prefrail/frail individuals.

For the subgroup analysis of the ATHIS, cross-tabs were used and a $\chi^{2}$-tests were conducted to assess the association between the proportion of people fulfilling the $150 \mathrm{~min}$ of aerobic physical activity and the proportion of those doing strength training at least twice a week. For all calculations, a statistical probability of $p<0.05$ was considered significant. Statistical software package SPSS 20.0 (SPSS Inc., Chicago, IL, USA) was used. 
Table 1 Aerobic physical activity level of 11 European countries

Table 2 Proportion in frailty categories in subjects $\geq 65$ years in 11 European countries

\begin{tabular}{|c|c|c|c|c|}
\hline & $\begin{array}{l}0 \mathrm{~min} / \text { week } \\
(\%)\end{array}$ & $\begin{array}{l}1-149 \mathrm{~min} / \text { week } \\
(\%)\end{array}$ & $\begin{array}{l}\geq 150 \mathrm{~min} / \text { week } \\
(\%)\end{array}$ & $\begin{array}{l}\geq 300 \mathrm{~min} / \text { week } \\
(\%)\end{array}$ \\
\hline Austria & 25.1 & 24.6 & 50.4 & 29.4 \\
\hline Czech Republic & 47.4 & 24.2 & 28.4 & 14.1 \\
\hline Denmark & 18.7 & 26.7 & 54.6 & 31.0 \\
\hline Estonia & 52.3 & 24.5 & 23.2 & 12.1 \\
\hline France & 49.0 & 26.0 & 25.0 & 11.7 \\
\hline Germany & 28.8 & 22.9 & 48.3 & 26.4 \\
\hline Italy & 65.0 & 16.8 & 18.2 & 8.9 \\
\hline Luxembourg & 36.5 & 21.9 & 41.6 & 21.9 \\
\hline Slovenia & 39.1 & 23.0 & 37.9 & 22.4 \\
\hline Spain & 51.0 & 15.0 & 34.0 & 21.1 \\
\hline Sweden & 24.6 & 21.3 & 54.1 & 30.7 \\
\hline
\end{tabular}

\begin{tabular}{|c|c|c|c|}
\hline \multirow[t]{2}{*}{ Country } & \multicolumn{3}{|c|}{ SHARE frailty index categories } \\
\hline & $\begin{array}{l}\text { Robust } \\
n(\%)\end{array}$ & $\begin{array}{l}\text { Prefrail } \\
n(\%)\end{array}$ & $\begin{array}{l}\text { Frail } \\
n(\%)\end{array}$ \\
\hline Austria & $1590(74.9)$ & $323(15.2)$ & $210(9.9)$ \\
\hline Czech Republic & 1979 (69.5) & $568(20.0)$ & $299(10.5)$ \\
\hline Denmark & $1459(77.8)$ & $260(13.9)$ & $157(8.4)$ \\
\hline Estonia & $1800(63.0)$ & 679 (23.8) & 379 (13.3) \\
\hline France & $1495(66.6)$ & $466(20.7)$ & $285(12.7)$ \\
\hline Germany & $1854(75.5)$ & $402(16.4)$ & $201(8.2)$ \\
\hline Italy & $1349(61.5)$ & $469(21.4)$ & $377(17.2)$ \\
\hline Luxembourg & $448(71.1)$ & $112(17.8)$ & $70(11.1)$ \\
\hline Slovenia & $876(63.7)$ & $297(21.6)$ & $202(14.7)$ \\
\hline Spain & $1892(59.4)$ & $764(24.0)$ & $528(16.6)$ \\
\hline Sweden & 2272 (81.3) & 379 (13.6) & $142(5.1)$ \\
\hline
\end{tabular}

\section{Results}

The EHIS data, providing the aerobic physical activity level of the people in the included 11 European countries, are shown in Table 1. Accordingly, the lowest proportion of all individuals who performed no aerobic physical activity at all was seen in Denmark and the highest in Italy. The proportion of people who performed 1-149 min of aerobic physical activity per week was reported as lowest in Spain and highest in Denmark. Additionally, the proportion of people performing $\geq 150$ min of aerobic physical activity and who therefore fulfilled the minimum recommended aerobic physical activity was lowest in Italy and highest in Denmark. The country with the lowest proportion of people who performed $\geq 300$ min per week aerobic physical activity was Italy, while the country with the highest being Denmark. Looking at the results of Austria, half of the participant performed $\geq 150 \mathrm{~min} /$ week of moderate aerobic physical activity (3rd place in the rankings) and about 30\% stated to do $\geq 300 \mathrm{~min} /$ week (3rd place in the rankings).
Data of the SHARE study showed that participants in these investigated 11 countries had a mean age of 73.8 years ( \pm 6.7 years) and $45.9 \%$ were male. Mean handgrip strength was $30.8( \pm 11.1) \mathrm{kg}$. Exhaustion was reported between $31.4 \%$ in Austria and $52.7 \%$ in Estonia, while weight loss was indicated among $6.6 \%$ participants in Germany to $10.6 \%$ in Italy. Sweden had the lowest reported proportion of slowness with $9.6 \%$ while in Slovenia the reported levels were at $28.4 \%$. Additionally, in Sweden $6.0 \%$ reported low activity level while the same was reported at $16.4 \%$ in Spain. The frailty prevalence of the included 11 European countries is shown in Table 2. Accordingly, the country with the highest frailty prevalence was Italy, the lowest in Sweden. The country with the highest prevalence of prefrailty was Spain, whereas Sweden once again had the lowest prevalence. Looking at the results, Austria had the 4 th lowest prevalence of frailty and the 3rd lowest prevalence of prefrailty.

Looking at the association between the ATHIS and the SHARE data, a significant negative correlation could be seen between the proportion of peo- 
Fig. 1 Correlation between the proportion of adult people conducting more than $150 \mathrm{~min}$ of aerobic physical activity/week and the proportion of prefrail or frail subjects $\geq 65$ years in 11 European countries. ('Correlations were calculated using Spearman's correlation coefficient)

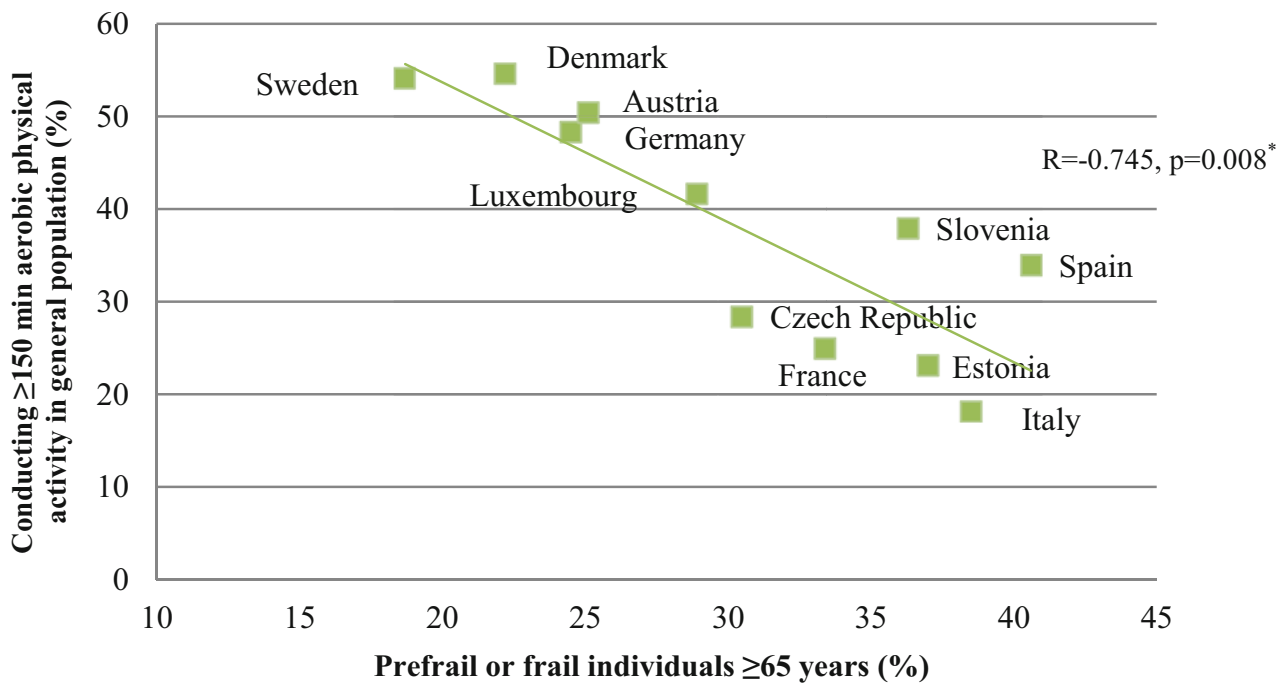

Fig. 2 Correlation between the proportion of adult people conducting more than 300 min of aerobic physical activity/week and the proportion of prefrail or frail subjects $\geq 65$ years in 11 European countries. ("Correlations were calculated using Spearman's correlation coefficient)

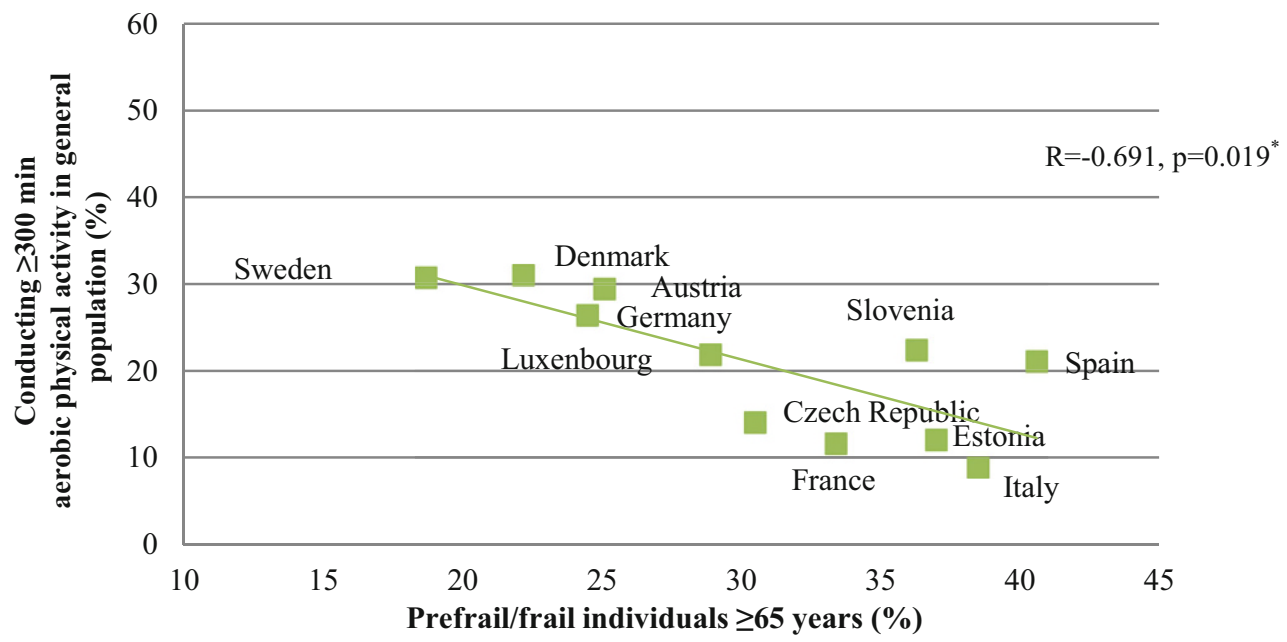

ple fulfilling the minimal aerobic physical activity recommendations and the proportion of prefrail or frail people in the respective countries $(R=-0.745$; $p=0.008$ ) (Fig. 1). There was also a significant correlation between the proportion of people fulfilling the optimal aerobic physical activity guidelines and the proportion of prefrail or frail subjects $(\mathrm{R}=-0.691$; $p=0.019$ ) (Fig. 2).

Concerning the association between aerobic physical activity and strength training, the ATHIS data showed that $52.0 \%$ of people fulfilling the minimum aerobic physical activity recommendations also conducted strength training at least twice a week, whereas $18.4 \%$ of the people who did not fulfil the minimum aerobic physical activity recommendations also performed strength training at least twice a week $(p<0.001)$.

\section{Discussion}

The results showed that in European countries with a high proportion of physically active subjects in the general population, the proportion of prefrailty or frailty is low in the elderly population, and vice versa. This shows the importance of fulfilling at least the minimum physical activity recommendations in order to prevent frailty. These results are even more remarkable when taking into account that the examined populations were different, namely the entire adult population ( $\geq 15$ years) with regard to the performed physical activity and on the other hand only the elderly ( $\geq 65$ years) for the frailty status.

An issue that needs to be mentioned is that the correlation was found between aerobic physical activity and frailty status. As frailty status is largely associated with sarcopenia [24] that might especially be related to strength training and to a lower degree to aerobic physical activity, an even higher correlation was expected between strength training and frailty proportions; however, in a subgroup analysis only a weak association, although significant, was shown between achieving the recommended amount of aerobic physical activity and achieving the same for strength training (half of the subjects who fulfilled the aerobic guidelines did not meet the minimum for strength training). Nonetheless, further analy- 
ses should examine the association between strength training and frailty status across Europe.

The European north-south gradient of physically active subjects is in line with other studies [25]; however, in comparison to other northern European countries Estonia showed a higher frailty prevalence, which might also be explained by differences in the socioeconomic status in previous decades. Interestingly, in northern European countries people also reported more opportunities for physical activity, frequent more often sports clubs and fitness centers, and are more self-reliant on themselves and not on the local community to provide physical training possibilities [25]. This north-south gradient was also reported in data analyzing the frailty status across Europe, stating that socioeconomic factors such as education level are responsible for the differences $[26,27]$. Thus, the observed differences in exercise behaviour and also in frailty status might be explained by the socioeconomic reasons, as less physical activity and higher prevalence of frailty are reported in poorer countries [26]. Additionally, cultural reasons that influence the different attitudes towards exercise and frailty status might be a further reason.

The major strength of this analysis was that a correlation study was performed on a European level for the first time. As the major limitation it should be mentioned that the study was only able to analyze the association between aerobic physical activity and prefrailty or frailty; however, as sarcopenia is related to frailty especially strength training is necessary to prevent frailty. It has also been taken into account that data on aerobic physical activity are self-reported. This might lead to an overestimation of physical activity [28].

\section{Conclusion}

Taken together, the findings strengthen the postulation that community-based approaches aimed at achieving physical activity recommendations and creating exercise friendly environments. In particular, the results should be taken into account in southern European countries, when planning public health interventions. This may be important in increasing physical activity levels, prevention of frailty and prevention of other adverse health outcomes.

Funding Open access funding provided by Medical University of Vienna.

\section{Compliance with ethical guidelines}

Conflict of interest S. Haider, I. Grabovac, and T.E. Dorner declare that they have no competing interests.

Ethical standards This article does not contain any studies with human participants or animals performed by any of the authors. Ethical approval was not necessary as this is a secondary analysis of open access previously published datasets.
Open Access This article is distributed under the terms of the Creative Commons Attribution 4.0 International License (http://creativecommons.org/licenses/by/4.0/), which permits unrestricted use, distribution, and reproduction in any medium, provided you give appropriate credit to the original author(s) and the source, provide a link to the Creative Commons license, and indicate if changes were made.

\section{References}

1. Fried LP, et al. Frailty in older adults: evidence for a phenotype. J Gerontol ABiol Sci Med Sci. 2001;56(3):M146-56.

2. Walston J, et al. Research agenda for frailty in older adults: toward a better understanding of physiology and etiology: summary from the American Geriatrics Society/National Institute on Aging Research Conference on Frailty in Older Adults. JAm Geriatr Soc. 2006;54(6):991-1001.

3. Santos-Eggimann B, et al. The Lausanne cohort Lc65+: a population-based prospective study of the manifestations, determinants and outcomes of frailty. BMC Geriatr. 2008;8:20.

4. Buckinx F, et al. Burden of frailty in the elderly population: perspectives for a public health challenge. Arch Public Health. 2015;73(1):19.

5. Clegg A, et al. Frailty in elderly people. Lancet. 2013;381(9868):752-62.

6. Bauman A, et al. Updating the evidence for physical activity: summative reviews of the epidemiological evidence, prevalence, and interventions to promote "active aging". Gerontologist. 2016;56(Suppl2):268-80.

7. Rolland Y, et al. Treatment strategies for sarcopenia and frailty. Med Clin North Am. 2011;95(3):427-38.

8. World Health Organization. Global recommendations on physical activity for health. 2011. Available from: http://www.who.int/dietphysicalactivity/factsheet_ recommendations/en/. Accessed on: $21^{\text {st } J u n e ~} 2018$

9. Titze S, Ring-Dimitriou S, Schober PH, Halbwachs C, Samitz G, Miko HC, et al. Österreichische Empfehlungen für gesundheitswirksame Bewegung. Wien: Bundesministeriumfür Gesundheit; 2010.

10. Braith RW, Stewart KJ. Resistance exercise training: its role in the prevention of cardiovascular disease. Circulation. 2006;113(22):2642-50.

11. Cruz-Jentoft AJ, et al. Sarcopenia: European consensus on definition and diagnosis: report of the European Working Group on Sarcopenia in older people. Age Ageing. 2010;39(4):412-23.

12. MitchellWK, etal. Sarcopenia, dynapenia, and theimpact of advancing age on human skeletal muscle size and strength; a quantitative review. Front Physiol. 2012;3:260.

13. Morley JE. Sarcopenia: diagnosis and treatment. J Nutr Health Aging. 2008;12(7):452-6.

14. Dodds RM, et al. Grip strength across the life course: normative data from twelve British studies. PLoS ONE. 2014;9(12):e113637.

15. Kallman DA, Plato CC, Tobin JD. The role of muscle loss in the age-related decline of grip strength: cross-sectional and longitudinal perspectives. J Gerontol. 1990;45(3):M82-M8.

16. Doherty TJ. Invited review: aging and sarcopenia. J Appl Physiol. 2003;95(4):1717-27.

17. Cadore EL, et al. Strength and endurance training prescription in healthy and frail elderly. Aging Dis. 2014;5(3):183-95.

18. Sipila S, Suominen H. Effects of strength and endurance training on thigh and leg muscle mass and composition in elderly women. JAppl Physiol. 1995;78(1):334-40. 
19. eurostat. Time spent on health-enhancing (non-workrelated) aerobicphysicalactivitybysex, ageandeducational attainmentlevel. 2017.

20. eurostat. European Health Interview Survey (EHIS wave 2) Methodologicalmanual. 2013.

21. Borsch-Supan A, et al. Data resource profile: the survey of health, ageing and retirement in europe (SHARE). Int J Epidemiol. 2013;42(4):992-1001.

22. Romero-Ortuno R, et al. A frailty instrument for primary care: findings from the Survey of Health, Ageing and Retirement in Europe (SHARE). BMC Geriatr. 2010;10:57.

23. Statistik Austria. Österreichische Gesundheitsbefragung 2014 - Hauptergebnisse des Austrian Health Interview Survey (ATHIS) und methodische Dokumentation. 2015.
24. Dent E, Kowal P, Hoogendijk EO. Frailty measurement in research and clinical practice: a review. Eur J Intern Med. 2016;31:3-10.

25. European Commission. Special Eurobarometer 412 “Sport and physical activity". 2014.

26. Santos-Eggimann B, et al. Prevalence of frailty in middleaged and older community-dwelling Europeans living in 10 countries. J Gerontol A Biol Sci Med Sci. 2009;64(6):67581.

27. Börsch-SupanA, et al. First results from the survey of health, ageing and retirement in Europe (2004-2007). Mannheim: Mannheim Research Institute for the Economics of Aging; 2008.

28. Sallis JF, Saelens BE. Assessment of physical activity by selfreport: status, limitations, and future directions. Res Q Exerc Sport. 2000;71(2 Suppl):1-14. 